Therapeutics

\section{Metoprolol is not effective for preventing acute exacerbations in COPD}

10.1136/bmjebm-2019-111313

Check for updates

Igho J Onakpoya

Nuffield Department of Primary Care Health Sciences, University of Oxford, Oxford, UK

Correspondence to: Dr Igho J Onakpoya, Primary Care, University of Oxford, Oxford OX12JD, UK; igho.onakpoya@phc. ox.ac.uk

Results of observational studies suggest that beta-blockers have a role in preventing acute exacerbations of COPD, however a recent randomised controlled trial demonstrates it may cause more harm than good.

Acute exacerbations of chronic obstructive pulmonary disease (COPD) are a major contributor to morbidity and mortality. Reductions in the frequency and severity of such exacerbations improve long-term clinical outcomes and quality of life. ${ }^{1}$ Previous meta-analyses of observational studies have suggested that betablockers may be beneficial in the management of COPD. ${ }^{23}$

The BLOCK COPD (Beta-Blockers for the Prevention of Acute Exacerbations of COPD) study was a multicentre, randomised, placebo-controlled clinical trial $(n=532)$ that assessed the effectiveness of extended-release metoprolol (a beta-1 selective adrenergic receptor blocker) in preventing acute exacerbations in adults with moderate or severe COPD (aged 40-85 years). ${ }^{4}$ The primary outcome was time until first exacerbation. Secondary outcomes included hospitalisations, adverse events and quality of life (measured by the St George's Respiratory Questionnaire and the COPD Assessment Test).

At the end of the treatment period (range 336-350 days), there was no significant difference in the median time until first exacerbation between metoprolol and placebo: 202 days versus 222 days, HR 1.05 (95\% CI 0.84 to 1.32). Neither was there any difference in the rates of exacerbations per person-year between groups. However, metoprolol was associated with a significantly increased risk of acute exacerbations resulting in hospitalisations: HR 1.91 (95\% CI 1.29 to 2.83). There were no significant differences in overall mortality, quality of life or frequency of adverse events between metoprolol and placebo.

The BLOCK COPD investigators used appropriate techniques to ensure randomisation and blinding, they conducted sample size analysis and used unadjusted and adjusted models to compare the outcomes between groups. However, the trial did not include patients at low risk of acute exacerbations, or those in whom the use of metoprolol (or other beta-blockers) was clinically indicated. That the trial was prematurely terminated makes it difficult to assess the risk of exacerbations between subgroups. The extent to

\section{EBM verdict}

EBM Verdict on: Dransfield MT, Voelker H, Bhatt $\mathrm{SP}$, et al. Metoprolol for the prevention of acute exacerbations of COPD. N Engl J Med 2019;20;380 (25):2429-39.

- In patients with COPD at high risk of exacerbations, metoprolol is not beneficial for preventive management.

which the results of the trial can be extrapolated to other betablocker class of drugs is also uncertain.

The results of the BLOCK COPD trial contradict those of previously published meta-analyses of observational studies. ${ }^{23}$ Both meta-analyses concluded that beta-blockers were significantly beneficial for COPD exacerbations and mortality. The results of both meta-analyses had substantial heterogeneity; furthermore, observational studies are at a greater risk of bias and confounding that often prevents firm conclusions to be drawn. ${ }^{5}$ More adequately powered randomised clinical trials are needed to confirm the findings of the BLOCK COPD trial and evaluate the benefit-harm balance of beta-blockers in subgroups of patients with COPD with different comorbid profiles.

Twitter Igho J Onakpoya @IOnakpoya

Contributors IJO wrote the manuscript.

Funding The authors have not declared a specific grant for this research from any funding agency in the public, commercial or not-for-profit sectors.

Competing interests None declared.

Patient consent for publication Not required.

Provenance and peer review Commissioned; internally peer reviewed.

๑ Author(s) (or their employer(s)) 2020. No commercial re-use. See rights and permissions. Published by BMJ.

To cite: Onakpoya IJ. BMJ Evidence-Based Medicine 2020;25:220.

ORCID iD

Igho J Onakpoya http://orcid.org/0000-0002-2420-0811

\section{References}

1 Anzueto A. Impact of exacerbations on COPD. Eur Respir Rev 2010;19:113-8.

2 Etminan M, Jafari S, Carleton B, et al. Beta-Blocker use and COPD mortality: a systematic review and meta-analysis. BMC Pulm Med 2012;12:48.

3 Du Q, Sun Y, Ding N, et al. Beta-Blockers reduced the risk of mortality and exacerbation in patients with COPD: a meta-analysis of observational studies. PLoS One 2014;9:e113048.

4 Dransfield MT, Voelker H, Bhatt SP, et al. Metoprolol for the prevention of acute exacerbations of COPD. N Engl J Med 2019;381:2304-14.

5 Viswanathan M, Berkman ND, Dryden DM, et al. Assessing risk of bias and confounding in observational studies of interventions or exposures: further development of the RTI item bank. Rockville (MD): Agency for Healthcare Research and Quality (US), 2013. https://www.ncbi.nlm.nih.gov/books/ NBK154461/ 